\title{
SELECTED PERSONAL CONDITIONS DETERMINING THE FREQUENCY OF CONSUMING GROUPS OF PRODUCTS AMONG ATHLETES PROFESSIONALLY TRAINING INDIVIDUAL SPORTS DISCIPLINES
}

original paper

( ) University School of Physical Education in Wroclaw

DOI: https://doi.org/10.5114/hm.2019.83997

\section{MARIA GACEK}

Department of Sports Medicine and Human Nutrition, University of Physical Education in Krakow, Krakow, Poland

\begin{abstract}
Purpose. Evaluation of the frequency of consuming food products depending on sex, age, and level of self-efficacy, optimism and life satisfaction in a group of athletes professionally training individual sports disciplines.

Methods. The research was performed among 346 individuals (214 men and 132 women). The author's personal consumption questionnaire, the General Self-Efficacy Scale, the Life Orientation Test-Revised, and the Satisfaction with Life Scale were used. The Mann-Whitney U Test, the Kruskal-Wallis test, and Spearman's rank correlation coefficients served to analyse the results.

Results. Women more often consumed vegetables, milk, and curd cheeses with reduced fat content; men more often consumed legume seeds, whole-fat curds, pork, vegetable juices, and energy drinks. The statistical analysis showed a positive correlation between the intensity of sense of efficacy and the frequency of consuming legume seeds, semi-skimmed milk, poultry, and isotonic drinks. The level of optimism was negatively correlated with the frequency of consuming light bread, sugary beverages, and energy drinks, while it positively correlated with the frequency of consuming fruit juices. Along with the increase in life satisfaction, the frequency of consumption of wholemeal bread increased, while that of fast food products decreased. Furthermore, it was demonstrated that along with age, the respondents more often included poultry and mineral water in their diets, and significantly less often consumed whole-fat milk, pork, sweets, and pastries.

Conclusions. Food choices varied depending on sex, age, and level of efficacy, dispositional optimism and life satisfaction. Key words: life satisfaction, sense of self-efficacy, dispositional optimism, personal resources, athletes, frequency of eating food products
\end{abstract}

\section{Introduction}

Maintaining health and optimizing the effects of sports training are favoured by applying a varied and balanced diet, with high nutrient density, covering the demand for increased energy, some nutrients, and fluids [1-3]. An illustration of current recommendations for athletes is the model of the Swiss pyramid, with sugar-free beverages at the base, and sweets, salty snacks, and sugary beverages at the top, between which there are groups of vegetables and fruit, whole grain cereals and legume products, protein products and oils, fats and nuts, recommended for consumption in a varied amount and frequency [4]. The model of the new Polish Pyramid of Physical Activity and Healthy Nutrition of the National Food and Nutrition
Institute in Warsaw of January 2016 also reflects a rational diet. The current dietary models emphasize the distinct importance of water and other sugar-free drinks for effective regulation of water and electrolyte balance, as well as vegetables and fruit (low- and medium-glycaemic products rich in dietary fibre, potassium, magnesium, vitamins $\mathrm{B}$, and antioxidants) for restoring antioxidant status and acid-base balance [2-5].

Behaviours conducive to health improvement (in athletes, also exercise ability), including rational dietary choices, are conditioned by a wide range of socio-economic, cultural, and personality factors [6-8]. Among the psychological features relevant to shaping health culture, personal resources occupy an important place, including a sense of one's own generalized

Correspondence address: Maria Gacek, Department of Sports Medicine and Human Nutrition, University of Physical Education in Krakow, al. Jana Pawła II 78, 31-571 Krakow, Poland, e-mail: maria.gacek@awf.krakow.pl

Received: November 27, 2018

Accepted for publication: February 25, 2019

Citation: Gacek M. Selected personal conditions determining the frequency of consuming groups of products among athletes professionally training individual sports disciplines. Hum Mov. 2019;20(3):56-65; doi: https://doi.org/10.5114/hm.2019.83997. 
efficacy and dispositional optimism, as well as one's level of satisfaction with life [8]. Self-efficacy, as a belief in the ability to achieve intended goals, promotes control over factors conditioning health: among others, eating behaviours. Also, a high intensity of dispositional optimism, increasing motivation and determination in achieving goals, is an important individual resource that stimulates health-promoting behaviours, also in the area of rational nutrition. The level of optimism shows a positive correlation with the intensity of one's sense of efficacy and satisfaction with life, which is also an important subjective indicator of health and quality of life [8]. For athletes, rational nutrition is not only a key factor in maintaining and improving health, but also a condition for optimizing training effects [1-3].

For this reason, research was undertaken regarding the importance of selected personal resources for the formation of dietary choices, important for health and exercise capacity among athletes training individual sports disciplines. Previous studies have shown a dependence between one's sense of generalized efficacy and dispositional optimism and the level of life satisfaction and the nutritional behaviours of team athletes $[9,10]$ and young women practising fitness $[11,12]$. This work is part of interdisciplinary research on the psychological determinants of nutritional behaviours among professional athletes.

The aim of the study was to analyse the frequency of consumption of selected groups of food products depending on sex, age, type of performed discipline, and the level of some personal resources (self-efficacy, dispositional optimism, and life satisfaction) in a group of athletes training different individual sports disciplines.

\section{Material and methods}

\section{Participants}

The study was conducted among a group of 346 individuals, including 214 men (aged 18-39 years, mean $[M] \pm$ standard deviation $[S D]: 20.91 \pm 3.49$ years) and 132 women (aged 18-37 years, $M \pm S D$ : $21.33 \pm 3.17$ years) training individual sports disciplines. The group consisted of athletes training swimming (35.26\%), track-and-field (24.85\%), ski jumping (11.56\%), weightlifting (13.87\%), and cross-country skiing (14.46\%). The basic criterion for open group selection was at least 3 years of experience in professional sports. The competitors underwent regular training at least 5 times a week, in over-time training units $(9.31 \pm 3.21$ hours per week). Athletes represented the level of the first (34.48\%) and second (65.52\%) sports classes, and their professional training experience ranged from 3 to 22 years $(M \pm S D$ : $14.11 \pm$ 3.71). The participants' education level was secondary (52.71\%), higher, including B.A. (17.73\%) and M.A. (14.78\%), and basic vocational (14.78\%).

\section{Procedure}

The author's questionnaire on the frequency of consumption of selected groups of food products (Figure 1) was used to assess the diet. The frequency of consumption of food products was evaluated with the use of a point scale, assigning a number to specific categories: several times a day (7), once a day (6), 4-6 times a week (5), 2-3 times a week (4), several times a month (3), once a month (2), and less frequently / never (1). The author's questionnaire for the diet assessment was subjected to a validation procedure, which showed high repeatability of the results.

The standardized General Self-Efficacy Scale (GSES) by Schwarzer, Jerusalem, and Juczyński was used to measure the sense of efficacy [8]. The GSES scale contains 10 statements; the higher the test result (in the range of 10-40 points), the higher the sense of generalized efficacy. The median of the raw GSES scores was $31 \pm 3(M \pm S D$ : $31.62 \pm 4.05$, $\min -\max$ : 20-40) for the examined men and $30 \pm 1.5(M \pm S D$ : $30.50 \pm 3.30$, min-max: 22-39) for the women.

To measure the level of dispositional optimism, the Life Orientation Test-Revised (LOT-R) by Scheier, Carver, and Bridges, adapted by Poprawa and Juczyński was used [8]. The LOT-R scale contains 10 statements (6 of which are diagnostic); the higher the test result (in the range of 0-24 points), the higher the level of optimism. The median of the raw results on the LOT-R scale was $16 \pm 3(M \pm S D: 16.01 \pm 4.45$, min-max: 2-19) among the studied men and, similarly, $16 \pm 2$ $(M \pm S D: 15.70 \pm 3.60$, min-max: 5-18) among the women.

The level of satisfaction with life was measured with the Satisfaction with Life Scale (SWLS) by Diener, Emmons, Larsen, and Griffin, adapted by Juczyński [8]. The SWLS contains 5 statements; the higher the test result (within the range of 5-35 points), the higher the sense of life satisfaction. The median of the raw scores on the SWLS was $23 \pm 3(M \pm S D: 22.33 \pm$ 5.06, min-max: 9-30) among the studied men and $22 \pm 2.5(M \pm S D: 21.70 \pm 3.90$, $\min -\max : 12-28)$ among the women. 


\section{HUMAN MOVEMENT}

M. Gacek, Athletes nutrition and personalityt

How often do you consume the given products? (Insert $\mathrm{X}$ in the appropriate column)

\begin{tabular}{|c|c|c|c|c|c|c|c|}
\hline Food products & $\begin{array}{c}\text { Several times } \\
\text { a day }\end{array}$ & Once a day & $\begin{array}{c}\text { 4-6 times } \\
\text { a week }\end{array}$ & $\begin{array}{l}\text { 2-3 times } \\
\text { a week }\end{array}$ & $\begin{array}{c}\text { Several times } \\
\text { a month }\end{array}$ & $\begin{array}{c}\text { Once } \\
\text { a month }\end{array}$ & $\begin{array}{c}\text { Less } \\
\text { frequently / } \\
\text { never }\end{array}$ \\
\hline \multicolumn{8}{|l|}{ Light bread } \\
\hline \multicolumn{8}{|c|}{ Wholemeal bread } \\
\hline \multicolumn{8}{|l|}{ Raw vegetables } \\
\hline \multicolumn{8}{|l|}{ Legume seeds } \\
\hline \multicolumn{8}{|l|}{ Fruit } \\
\hline \multicolumn{8}{|c|}{ Semi-skimmed milk } \\
\hline \multicolumn{8}{|l|}{ Whole milk } \\
\hline \multicolumn{8}{|c|}{ Naturally fermented dairy } \\
\hline \multicolumn{8}{|c|}{ Semi-skimmed curd } \\
\hline \multicolumn{8}{|c|}{ Whole-fat curd } \\
\hline \multicolumn{8}{|l|}{ Fish } \\
\hline \multicolumn{8}{|l|}{ Poultry } \\
\hline \multicolumn{8}{|l|}{ Pork } \\
\hline \multicolumn{8}{|l|}{ Different nuts } \\
\hline \multicolumn{8}{|l|}{ Sweets/pastries } \\
\hline \multicolumn{8}{|l|}{ Fast food } \\
\hline \multicolumn{8}{|l|}{ Fruit juices } \\
\hline \multicolumn{8}{|l|}{ Vegetable juices } \\
\hline \multicolumn{8}{|c|}{ Sugary beverages } \\
\hline \multicolumn{8}{|c|}{ Energy drinks } \\
\hline \multicolumn{8}{|l|}{ Mineral water } \\
\hline Isotonic drinks & & & & & & & \\
\hline
\end{tabular}

Figure 1. The author's own questionnaire on the frequency of consumption of selected groups of food products

\section{Statistical analysis}

The analysis of the results was carried out with the PQStat ver. 1.6.6.202 statistical package. Data distribution was verified with the Shapiro-Wilk test (no normal distribution). Comparisons of the frequency of consuming products according to gender were made with the Mann-Whitney $U$ test, and depending on type of discipline, via the Kruskal-Wallis and the DunnBonferroni post-hoc test. The Spearman's rank correlation coefficients served to analyse the relationship between the intensity of psychological traits and age and the frequency of consuming individual product groups. The dependencies between age and the intensity of psychological traits were assessed with the Spearman's rank correlation coefficients. The results of the GSES, LOT-R, and SWLS, depending on the discipline, were analysed via the Kruskal-Wallis and the Dunn-Bonferroni post-hoc tests. The test probability was assumed to be significant at $p<0.05$, and highly significant at $p<0.01$ and $p<0.001$.

\section{Ethical approval}

The research related to human use has been complied with all the relevant national regulations and institutional policies, has followed the tenets of the Declaration of Helsinki, and has been approved by the authors' institutional review board or an equivalent committee.

\section{Informed consent}

Informed consent has been obtained from all individuals included in this study. 


\section{Results}

On the basis of the median $(\mathrm{Me})$ value, it was found that athletes most often, i.e. $4-6$ times a week $(M e=5)$, consumed fruit $( \pm 1)$, mineral water (women: \pm 2 , men: \pm 1.5 ), and isotonic drinks ( \pm 1.5 ). Typically, $2-3$ times a week $(M e=4)$, the following were consumed: light bread $( \pm 1)$, raw vegetables $( \pm 1)$, poultry (women: \pm 0.5 , men: \pm 1 ), as well as sweets/pastries $( \pm 1)$ and fruit juices (women: \pm 1 , men: \pm 1.5 ). The participants consumed wholemeal bread $( \pm 1)$, legume seeds $( \pm 0.5)$, naturally fermented dairy products $( \pm 1)$, semi-skimmed curds (women: \pm 1 , men: \pm 0.5 ), fish $( \pm 0.5$ ), pork (women: \pm 1 , men: \pm 0.5 ), nuts $( \pm 0.5$ ), fast food ( \pm 0.5 ), and sugary drinks $( \pm 1)$ several times a month $(\mathrm{Me}=3)$. With lower frequency, once a month $(M e=2 \pm 1)$, they chose high-fat curd and vegetable juices (Table 1).

The analysis of consumption frequency of food groups according to sex showed that women consumed the following significantly more often: raw vegetables $(p<0.05)$, milk $(p<0.001)$, and curd with reduced fat content $(p<0.05)$; the men's diet included the following significantly more often: legume seeds $(p<0.05)$, high-fat curd $(p<0.05)$, pork $(p<0.01)$, vegetable juices $(p<0.01)$, and energy drinks $(p<0.001)$ (Table 1$)$.

There was also a significant variation in the frequency of consuming some groups of food products depending on the type of practised sport. Athletes of particular disciplines consumed the following products with varied frequency: wholemeal bread $(p<0.05)$, legume seeds $(p<0.01)$, whole-fat milk $(p<0.001)$, naturally fermented dairy products $(p<0.01)$, semiskimmed $(p<0.05)$ and whole-fat $(p<0.001)$ curd cheese, poultry $(p<0.01)$, fish $(p<0.001)$, fast food products $(p<0.05)$, sweets and pastries $(p<0.01)$, sweetened fizzy drinks $(p<0.001)$, isotonic beverages $(p<0.05)$, energy drinks $(p<0.001)$, and mineral water $(p<0.01)$ (Table 2).

Statistical analysis showed significant correlations between age and the frequency of consuming some groups of food products by the athletes. With increasing age, the frequency of consuming poultry $(p<0.05)$

Table 1. Frequency of consuming food products depending on gender among athletes practising individual sports disciplines (descriptive statistics and significance of differences)

\begin{tabular}{|c|c|c|c|c|c|c|c|c|c|}
\hline \multirow[b]{2}{*}{ Food products } & \multicolumn{4}{|c|}{ Women } & \multicolumn{4}{|c|}{ Men } & \multirow[b]{2}{*}{$p$} \\
\hline & $M \pm S D$ & $\begin{array}{l}\text { Min- } \\
\max \end{array}$ & $\begin{array}{l}\text { Q25- } \\
\text { Q75 }\end{array}$ & $M e \pm Q D$ & $M \pm S D$ & $\begin{array}{l}\text { Min- } \\
\max \end{array}$ & $\begin{array}{l}\text { Q25- } \\
\text { Q75 }\end{array}$ & $M e \pm Q D$ & \\
\hline Light bread & $3.68 \pm 1.50$ & $1-7$ & $3-5$ & $4 \pm 1$ & $3.73 \pm 1.52$ & $1-7$ & $3-5$ & $4 \pm 1$ & 0.716 \\
\hline Wholemeal bread & $3.36 \pm 1.30$ & $1-7$ & $3-5$ & $3 \pm 1$ & $3.37 \pm 1.45$ & $1-7$ & $3-5$ & $3 \pm 1$ & 0.951 \\
\hline Raw vegetables & $4.21 \pm 1.50$ & $1-7$ & $3-5$ & $4 \pm 1$ & $3.86 \pm 1.44$ & $1-7$ & $3-5$ & $4 \pm 1$ & $0.038^{*}$ \\
\hline Legume seeds & $2.92 \pm 0.94$ & $1-5$ & $2-3$ & $3 \pm 0.5$ & $3.16 \pm 0.96$ & $1-6$ & $3-4$ & $3 \pm 0.5$ & $0.048^{*}$ \\
\hline Fruit & $5.17 \pm 1.27$ & $2-7$ & $4-6$ & $5 \pm 1$ & $4.90 \pm 1.19$ & $2-7$ & $4-6$ & $5 \pm 1$ & 0.061 \\
\hline Semi-skimmed milk & $4.33 \pm 1.51$ & $1-7$ & $3-6$ & $4 \pm 1.5$ & $3.55 \pm 1.74$ & $1-7$ & $2-5$ & $3 \pm 1.5$ & $<0.001^{*}$ \\
\hline Whole milk & $2.71 \pm 1.70$ & $1-6$ & $1-4$ & $2 \pm 1.5$ & $2.95 \pm 1.46$ & $1-6$ & $2-4$ & $3 \pm 1$ & 0.054 \\
\hline Naturally fermented dairy & $3.48 \pm 1.78$ & $1-7$ & $3-5$ & $3 \pm 1$ & $3.27 \pm 1.31$ & $1-7$ & $2-4$ & $3 \pm 1$ & 0.197 \\
\hline Semi-skimmed curd & $3.08 \pm 1.14$ & $1-6$ & $2-4$ & $3 \pm 1$ & $2.80 \pm 1.22$ & $1-6$ & $2-3$ & $3 \pm 0.5$ & $0.023 *$ \\
\hline Whole-fat curd & $2.12 \pm 1.30$ & $1-6$ & $1-3$ & $2 \pm 1$ & $2.30 \pm 1.05$ & $1-5$ & $1-3$ & $2 \pm 1$ & $0.031 *$ \\
\hline Fish & $2.52 \pm 0.84$ & $1-5$ & $2-3$ & $3 \pm 0.5$ & $2.71 \pm 1.03$ & $1-6$ & $2-3$ & $3 \pm 0.5$ & 0.102 \\
\hline Poultry & $3.73 \pm 1.13$ & $1-7$ & $3-4$ & $4 \pm 0.5$ & $3.76 \pm 1.17$ & $1-7$ & $3-5$ & $4 \pm 1$ & 0.445 \\
\hline Pork & $2.71 \pm 0.98$ & $1-5$ & $2-4$ & $3 \pm 1$ & $3.88 \pm 0.97$ & $1-6$ & $3-4$ & $3 \pm 0.5$ & $0.008^{*}$ \\
\hline Different nuts & $2.71 \pm 0.87$ & $1-6$ & $2-3$ & $3 \pm 0.5$ & $2.78 \pm 1.04$ & $1-6$ & $2-3$ & $3 \pm 0.5$ & 0.643 \\
\hline Sweets/pastries & $3.82 \pm 1.16$ & $1-7$ & $3-5$ & $4 \pm 1$ & $3.75 \pm 1.20$ & $1-7$ & $3-5$ & $4 \pm 1$ & 0.696 \\
\hline Fast food & $2.56 \pm 0.89$ & $1-5$ & $2-3$ & $3 \pm 0.5$ & $2.68 \pm 0.89$ & $1-6$ & $2-3$ & $3 \pm 0.5$ & 0.151 \\
\hline Fruit juices & $4.25 \pm 1.44$ & $1-7$ & $3-5$ & $4 \pm 1$ & $4.33 \pm 1.46$ & $1-7$ & $3-6$ & $4 \pm 1.5$ & 0.608 \\
\hline Vegetable juices & $1.98 \pm 1.13$ & $1-6$ & $1-3$ & $2 \pm 1$ & $2.27 \pm 1.14$ & $1-7$ & $1-3$ & $2 \pm 1$ & $0.003^{*}$ \\
\hline Sugary beverages & $3.20 \pm 1.23$ & $1-7$ & $2-4$ & $3 \pm 1$ & $3.14 \pm 1.18$ & $1-6$ & $2-4$ & $3 \pm 1$ & 0.963 \\
\hline Energy drinks & $2.14 \pm 1.23$ & $1-7$ & $2-3$ & $2 \pm 0.5$ & $2.99 \pm 1.40$ & $1-7$ & $2-4$ & $3 \pm 1$ & $<0.001^{*}$ \\
\hline Mineral water & $4.55 \pm 1.97$ & $1-7$ & $2-6$ & $5 \pm 2$ & $4.69 \pm 1.77$ & $1-7$ & $3-6$ & $5 \pm 1.5$ & 0.600 \\
\hline Isotonic drinks & $4.76 \pm 1.76$ & $1-7$ & $3-6$ & $5 \pm 1.5$ & $4.66 \pm 1.76$ & $1-7$ & $3-6$ & $5 \pm 1.5$ & 0.082 \\
\hline
\end{tabular}

$M$ - arithmetic mean, $S D$ - standard deviation, Min-max - minimum-maximum, Q25-Q75 - lower quartile-upper quartile, $M e$ - median, $Q D$ - quartile deviation, $p$ - significance of statistical differences in the Mann-Whitney $U$ Test * statistically significant values 


\section{HUMAN MOVEMENT}

M. Gacek, Athletes nutrition and personalityt

Table 2. Frequency of consuming food products depending on the type of practised sport (descriptive statistics and significance of differences)

\begin{tabular}{|c|c|c|c|c|c|c|}
\hline \multirow[t]{2}{*}{ Food products } & $\begin{array}{l}\text { Cross-country } \\
\text { skiing }\end{array}$ & Track-and-field & Weightlifting & Swimming & Ski jumping & \multirow[t]{2}{*}{$p$} \\
\hline & $M e \pm Q D$ & $M e \pm Q D$ & $M e \pm Q D$ & $M e \pm Q D$ & $M e \pm Q D$ & \\
\hline Light bread & $2.5 \pm 0.6$ & $3.0 \pm 0.5$ & $3.0 \pm 0.5$ & $3.0 \pm 1.0$ & $3.0 \pm 0.5$ & 0.080 \\
\hline Wholemeal bread & $3.0 \pm 1.1$ & $3.0 \pm 1.0$ & $3.5 \pm 1.0$ & $3.0 \pm 1.0$ & $3.0 \pm 1.0$ & $0.036^{*}$ \\
\hline Raw vegetables & $4.5 \pm 1.0$ & $4.0 \pm 1.0$ & $4.0 \pm 0.0$ & $4.0 \pm 1.0$ & $4.0 \pm 1.0$ & 0.894 \\
\hline Legume seeds & $3.0 \pm 0.0^{\mathrm{ab}}$ & $3.0 \pm 0.0^{\mathrm{a}}$ & $3.5 \pm 0.5^{\mathrm{b}}$ & $3.0 \pm 0.5^{\mathrm{ab}}$ & $3.0 \pm 0.0^{\mathrm{ab}}$ & $0.008^{*}$ \\
\hline Fruit & $5.0 \pm 0.6$ & $5.0 \pm 1.6$ & $5.0 \pm 1.0$ & $5.0 \pm 1.0$ & $5.0 \pm 0.9$ & 0.778 \\
\hline Semi-skimmed milk & $3.5 \pm 1.1$ & $3.0 \pm 1.6$ & $3.5 \pm 1.5$ & $4.0 \pm 2.0$ & $4.0 \pm 1.4$ & 0.898 \\
\hline Whole milk & $2.0 \pm 0.6^{\mathrm{ab}}$ & $2.0 \pm 1.0^{\mathrm{a}}$ & $3.0 \pm 1.5^{\mathrm{abc}}$ & $3.0 \pm 1.5^{\mathrm{b}}$ & $3.0 \pm 1.0^{\mathrm{c}}$ & $<0.001 *$ \\
\hline Naturally fermented dairy & $3.0 \pm 1.0^{\mathrm{ab}}$ & $3.0 \pm 1.4^{\mathrm{a}}$ & $3.0 \pm 1.0^{\mathrm{a}}$ & $3.0 \pm 0.5^{\mathrm{a}}$ & $4.0 \pm 0.9^{b}$ & $0.001 *$ \\
\hline Semi-skimmed curd & $3.0 \pm 1.1^{\mathrm{ab}}$ & $3.0 \pm 0.5^{\mathrm{a}}$ & $3.0 \pm 0.5^{\mathrm{ab}}$ & $3.0 \pm 1.0^{\mathrm{b}}$ & $3.0 \pm 0.5^{\mathrm{ab}}$ & $0.044^{*}$ \\
\hline Whole-fat curd & $1.5 \pm 0.6^{\mathrm{a}}$ & $2.0 \pm 1.0^{\mathrm{a}}$ & $2.5 \pm 0.5^{\mathrm{ab}}$ & $3.0 \pm 1.0^{\mathrm{b}}$ & $2.0 \pm 0.5^{\mathrm{ab}}$ & $<0.001 *$ \\
\hline Fish & $2.0 \pm 1.0^{\mathrm{a}}$ & $3.0 \pm 0.5^{\mathrm{ab}}$ & $3.0 \pm 0.5^{\mathrm{ab}}$ & $3.0 \pm 0.5^{\mathrm{b}}$ & $3.0 \pm 0.9^{\mathrm{b}}$ & $<0.001 *$ \\
\hline Poultry & $3.0 \pm 0.6^{\mathrm{a}}$ & $4.0 \pm 0.9^{\mathrm{b}}$ & $4.0 \pm 0.0^{\mathrm{ab}}$ & $4.0 \pm 1.0^{\mathrm{b}}$ & $4.0 \pm 0.9^{\mathrm{ab}}$ & 0.006 * \\
\hline Pork & $3.0 \pm 1.1$ & $3.0 \pm 0.4$ & $3.0 \pm 0.5$ & $3.0 \pm 0.5$ & $3.0 \pm 0.5$ & 0.240 \\
\hline Different nuts & $3.0 \pm 0.5$ & $3.0 \pm 0.5$ & $3.0 \pm 0.5$ & $3.0 \pm 0.5$ & $3.0 \pm 0.5$ & 0.408 \\
\hline Sweets/pastries & $4.0 \pm 0.6^{\mathrm{ab}}$ & $3.0 \pm 0.9^{\mathrm{ab}}$ & $3.0 \pm 0.5^{\mathrm{a}}$ & $4.0 \pm 0.5^{\mathrm{b}}$ & $4.0 \pm 0.5^{\mathrm{ab}}$ & $0.001^{*}$ \\
\hline Fast food & $3.0 \pm 0.5^{\mathrm{a}}$ & $3.0 \pm 0.5^{\mathrm{b}}$ & $3.0 \pm 0.5^{\mathrm{ab}}$ & $3.0 \pm 0.5^{\mathrm{ab}}$ & $3.0 \pm 0.5^{\mathrm{ab}}$ & $0.020^{*}$ \\
\hline Fruit juices & $4.0 \pm 0.5$ & $4.0 \pm 1.0$ & $4.0 \pm 0.5$ & $4.0 \pm 1.0$ & $4.0 \pm 1.4$ & 0.277 \\
\hline Vegetable juices & $2.0 \pm 0.5$ & $2.0 \pm 1.0$ & $2.0 \pm 1.0$ & $2.0 \pm 1.0$ & $3.0 \pm 0.9$ & 0.065 \\
\hline Sugary beverages & $2.0 \pm 0.5^{\mathrm{a}}$ & $3.0 \pm 0.9^{b}$ & $2.0 \pm 0.5^{\mathrm{a}}$ & $3.0 \pm 0.5^{\mathrm{bc}}$ & $4.0 \pm 0.5^{\mathrm{bc}}$ & $<0.001 *$ \\
\hline Energy drinks & $1.0 \pm 0.6^{\mathrm{a}}$ & $3.0 \pm 0.5^{\mathrm{c}}$ & $2.0 \pm 0.5^{\mathrm{ab}}$ & $3.0 \pm 1.0^{\mathrm{bc}}$ & $4.0 \pm 1.0^{\mathrm{bc}}$ & $<0.001 *$ \\
\hline Mineral water & $3.5 \pm 1.0^{\mathrm{a}}$ & $6.0 \pm 1.0^{\mathrm{b}}$ & $5.0 \pm 1.5^{\mathrm{b}}$ & $4.5 \pm 2.0^{\mathrm{ab}}$ & $5.0 \pm 1.0^{\mathrm{ab}}$ & $0.002^{*}$ \\
\hline Isotonic drinks & $6.0 \pm 1.6^{\mathrm{b}}$ & $4.0 \pm 1.5^{\mathrm{ab}}$ & $5.0 \pm 1.0^{\mathrm{ab}}$ & $5.0 \pm 2.0^{\mathrm{ab}}$ & $4.0 \pm 1.0^{\mathrm{a}}$ & $0.018^{*}$ \\
\hline
\end{tabular}

$M e$ - median, $Q D$ - quartile deviation, $p$ - significance of statistical differences in the Kruskal-Wallis test

with the post-hoc Dunn-Bonferroni test

a, b, c significant differences between disciplines marked by different letters, lack of significant differences marked by the same letter

* statistically significant values

and mineral water grew $(p<0.01)$, while the frequency of consuming whole-fat milk $(p<0.05)$, pork $(p<0.05)$, as well as sweets and pastries $(p<0.001)$ declined (Table 3).

The study revealed a positive correlation between the intensity of self-efficacy and the frequency of consuming legume seeds $(p<0.05)$, semi-skimmed milk $(p<0.05)$, poultry $(p<0.05)$, and isotonic drinks $(p<$ $0.05)$. The level of optimism was negatively correlated with the frequency of consuming light bread $(p<0.05)$, cola-type sugary drinks $(p<0.05)$, and energy drinks $(p<0.001)$, and positively correlated with the frequency of consuming fruit juices $(p<0.05)$. Along with the increase in intensity of life satisfaction, the frequency of wholemeal bread consumption grew $(p<0.05)$, while the frequency of consumption of fast food products declined $(p<0.001)$ (Table 3).

The level of the analysed psychological traits (sense of self-efficacy, dispositional optimism, and life satis- faction) significantly increased along with the age of the respondents $(p<0.01)$. The level of optimism among individuals training track-and-field $(16.67 \pm 3.88)$ and weightlifting $(17.57 \pm 3.28)$ was significantly higher than in those practising cross-country skiing (13.88 $\pm 4.22)(p<0.01)$. The intensity of optimism among people training swimming $(15.48 \pm 4.47)$ and ski jumping $(16.37 \pm 4.47)$ did not significantly differ from that in athletes of other disciplines $(p>0.05)$. The level of self-efficacy (on the GSES scale) or life satisfaction (on the SWLS scale) did not differ among the competitors of particular disciplines $(p>0.05)$.

\section{Discussion}

The research among a group of professional athletes practising individual sports disciplines showed a diversity in dietary choices depending on sex and the type of performed discipline, as well as a relation- 
Table 3. Correlation coefficients between the intensity of personal resources (sense of efficacy, optimism, and life satisfaction) and the frequency of consuming selected groups of products among athletes professionally training individual sports disciplines (Spearman's $\rho$ )

\begin{tabular}{|c|c|c|c|c|}
\hline \multirow{2}{*}{ Food products } & \multicolumn{4}{|c|}{ Spearman's $\rho$} \\
\hline & $\begin{array}{c}\text { General Self-Efficacy } \\
\text { Scale }\end{array}$ & $\begin{array}{l}\text { Life Orientation } \\
\text { Test-Revised }\end{array}$ & $\begin{array}{c}\text { Satisfaction } \\
\text { with Life Scale }\end{array}$ & Age \\
\hline Light bread & -0.12 & $-0.15^{*}$ & -0.01 & 0.01 \\
\hline Wholemeal bread & 0.13 & 0.08 & $0.16^{*}$ & 0.04 \\
\hline Raw vegetables & -0.02 & 0.07 & -0.05 & 0.02 \\
\hline Legume seeds & $0.15^{*}$ & 0.07 & -0.01 & -0.08 \\
\hline Fruit & -0.01 & 0.10 & 0.05 & 0.03 \\
\hline Semi-skimmed milk & $0.17^{*}$ & 0.05 & -0.02 & 0.02 \\
\hline Whole milk & -0.02 & -0.07 & -0.08 & $-0.13^{*}$ \\
\hline Naturally fermented dairy & 0.04 & -0.06 & 0.04 & -0.07 \\
\hline Semi-skimmed curd & 0.03 & 0.00 & -0.03 & 0.01 \\
\hline Whole-fat curd & 0.07 & 0.15 & -0.00 & -0.08 \\
\hline Fish & 0.03 & -0.06 & 0.05 & 0.03 \\
\hline Poultry & $0.16^{*}$ & 0.03 & -0.12 & $0.11^{*}$ \\
\hline Pork & 0.13 & 0.12 & 0.01 & $-0.12^{*}$ \\
\hline Different nuts & 0.05 & 0.01 & 0.08 & 0.01 \\
\hline Sweets/pastries & -0.02 & -0.07 & -0.03 & $-0.22^{* * *}$ \\
\hline Fast food & -0.00 & -0.09 & $-0.27 * * *$ & -0.02 \\
\hline Fruit juices & 0.11 & $0.16^{*}$ & 0.04 & 0.04 \\
\hline Vegetable juices & -0.11 & 0.06 & -0.00 & -0.02 \\
\hline Sugary beverages & -0.04 & $-0.16^{*}$ & -0.11 & -0.01 \\
\hline Energy drinks & -0.05 & $-0.23 * * *$ & -0.08 & 0.05 \\
\hline Mineral water & 0.12 & 0.12 & 0.05 & $0.15^{* *}$ \\
\hline Isotonic drinks & $0.14 *$ & -0.08 & -0.07 & -0.09 \\
\hline
\end{tabular}

Statistically significant values: ${ }^{*} p<0.05,{ }^{* *} p<0.01,{ }^{* * *} p<0.001$

ship between age and the analysed personal resources and the consumption of some groups of food products.

The nutritional deficiencies described in the group of athletes training individual sports disciplines particularly regarded the insufficient frequency of consuming recommended products, including vegetables and fruit, wholemeal products, milk and dairy products (among others, those fermented), sea fish, and nuts. These abnormalities may reduce the nutritional value and health benefits of the diet because of the risk of low supply of digestible carbohydrates and dietary fibre, calcium, vitamins and other antioxidants, as well as unsaturated acids, including omega 3 polyunsaturated fatty acids. Potential food shortages in this area may generate decreased exercise capacity owing to the special role of carbohydrates in the energy of physical exercise, of calcium in regulating skeletal muscle contractions, and of antioxidant vitamins in eliminating the effects of oxidative stress developing under the conditions of intense physical exercise [1-5]. The observed nutritional anomalies corresponded with tendencies described by other authors in various groups of athletes performing team and individual disciplines, including Polish team sports players [9, 13, 14], professional English footballers [15], professional British rugby players [16], Australian football players [17], Lithuanian sportsmen of endurance disciplines [18], women training medium- and long-distance running [19], racecar drivers [20], and Portuguese athletes [21]. The following were found in the case of the Lithuanian endurance disciplines: carbohydrate deficiencies $(80.8 \%)$ and excess fats, saturated fatty acids and cholesterol (> 70\%) [18]. Race-car drivers showed insufficient intake of some nutrients, including energy, carbohydrates, dietary fibre, and folic acid [20], which could have resulted from insufficient consumption of highdensity food products, such as cereals, vegetables, and fruit. Also, among high-class Portuguese athletes, 
the diet was unbalanced, characterized by low carbohydrate supply (49\%), oversupply of protein (27\%), and a deficit in the supply of some vitamins $\left(\mathrm{D}, \mathrm{E}, \mathrm{B}_{9}\right)$ and minerals (Mg, Ca) [21]. Unbalanced supply of some nutrients, including carbohydrates, vitamins (antioxidants and group B), mineral salts (potassium and magnesium), and fibre, has also been described in other groups of athletes training various endurance disciplines [22-25]. Athletes' diets should instead be optimized and adapted to one's needs, sex, and type of discipline [21]. In turn, among Polish amateur mountain bikers, the highest rate in health-promoting behaviours was demonstrated in the area of positive eating habits [26].

The discussed research also showed a diversification in some food choices depending on sex, with the indication of more rational decisions among women than men. These were particularly related to more frequent consumption of recommended products, including raw vegetables and dairy products with reduced fat content, and less frequent consumption of less recommended products, such as those with high levels of saturated fatty acids (fatty curd, pork) and simple sugars (energy drinks). However, different trends were described in the consumption of legume seeds and vegetable juices (more often consumed by men). Other authors also pointed to differences in the consumption frequency of some products, including fruit and vegetables, depending on sex [27]. The larger scale of consuming less recommended products (rich in saturated fatty acids and simple sugars) among men referred to the trends demonstrated among young Spanish players [28], youth from Warsaw sports schools [29], and teenage youth from Lesser Poland [30]. The women's tendency to apply more rational dietary choices was also described in other groups of athletes, including high-class Portuguese athletes during the preparatory and starting period [21]. Differences in nutrition depending on sex were also demonstrated among Lithuanian athletes of endurance disciplines, with an indication of carbohydrate, protein, omega 3, dietary fibre, group B vitamins, and mineral salts (Ca, $\mathrm{K}, \mathrm{Fe}, \mathrm{Zn}$, $\mathrm{P}, \mathrm{Mn}$ ) in women's diets [18]. Research also showed a diversification of some factors determining the dietary choices of athletes depending on sex, with a greater tendency among women to choose known and aromatic products [31].

The differences in the frequency of consuming some product groups, both those recommended (including wholemeal bread, legume seeds, fermented dairy products, fish, isotonic drinks, mineral water) and those not recommended in the rational nutrition of athletes (fast food, pastries, sweetened fizzy beverages, energy drinks), do not allow for unambiguous assessment of the scale of rational dietary choices among athletes of particular disciplines at this level of analysis. It seems justified to continue research in this area, taking a more complex scope and model of research into account. However, some dietary tendencies among athletes from various disciplines can be explained by the nature and conditions of performing physical efforts. Within this context, one can point to the frequency of consuming mineral water and isotonic drinks, fluids recommended for the effective hydration of athletes. Mineral water was most often drunk by athletes who trained track-and-field and weightlifting, and least often by those engaging in cross-country skiing. In turn, isotonic drinks were most often consumed by athletes practising cross-country skiing, and least often by ski jumpers. The observed trends correspond with the recommendation for using isotonic beverages to replenish fluids (and energy substrates) during prolonged physical exercise [2-3].

The presented study revealed a relationship between age and the frequency of consuming some product groups, with a tendency towards more rational choices along with age. These trends concerned, in particular, the more frequent consumption of recommended products, including poultry and mineral water, and less frequent consumption of less recommended products, including whole-fat milk, pork, sweets and pastries. Similar tendencies towards more rational dietary behaviours of athletes along with age (experience and sports level) have also been described among team sports competitors [14, 32].

The research also showed a relationship between the level of one's generalized efficacy, dispositional optimism, and life satisfaction and the frequency of consuming some groups of products, with a tendency for sportspersons with a higher intensity of personal resources to make more rational choices. These tendencies particularly concerned greater consumption of recommended products, including legume seeds, semiskimmed milk, poultry, and isotonic drinks (in athletes with a higher sense of generalized efficacy), fruit juices (in those with a high level of optimism), and wholemeal bread (in respondents with higher life satisfaction). At the same time, there was a tendency towards lower consumption of less preferred products, such as light bread, cola-type beverages, and energy drinks (along with an increase in optimism) and fast food products (along with increased satisfaction with life).

A more beneficial image of dietary choices concerned athletes convinced of their own efficacy, being 
more optimistic and satisfied with life. The presented dependences, indicating the importance of the analysed psychological characteristics for the formation of sports nutrition choices, are justified and remain in line with the results of other studies. More rational dietary choices of athletes with a high sense of selfefficacy may be explained by the belief that they can achieve specific goals, including health-related ones, by exercising control over their determinants. High intensity of dispositional optimism, increasing motivation and determination in achieving goals, is an important health resource that stimulates health-promoting behaviours, also in the area of rational nutrition. Optimism shows a positive correlation with life satisfaction, sense of efficacy, as well as internal control [8, 33, 34].

A rational dietary model, including the right amount of products with high nutritional density, with whole grain cereals, vegetables and fruit, low-fat dairy fermented products, as well as fish and nuts, is an important factor in raising health potential and supporting athletes' efforts [1-5]. The results of the author's research, suggesting more rational dietary choices of athletes with a higher intensity of self-efficacy, being more optimistic and satisfied with life, refer to a larger scale of rational nutritional behaviours in other population groups, including athletes, individuals undertaking recreational physical activity, and students. More rational dietary choices of athletes with a high level of generalized self-efficacy were described among juniors training football [9] and Polish players of American football [10]. Positive relationships of high satisfaction with life and optimism with rational dietary behaviours were observed among young women recreationally training fitness and fitness instructors [12, 35]. Lipowski [36] also showed a positive correlation between the level of optimism and certain health behaviours among a group of women practising sports. In turn, Posadzki et al. [37] revealed significant positive effects of positively correlated psychological traits, including sense of self-efficacy, optimism, and sense of coherence, on the health-promoting behaviour of Polish students. A larger scale of health-promoting behaviours, including positive nutrition practices, along with an increase in the level of life satisfaction was also described in a group of Polish teaching specialization students [38]. Relationships of life satisfaction with some health conditions including nutritional ones were also confirmed by Iranian studies, showing a positive correlation between the level of life satisfaction and the number of meals, regular consumption of breakfast, as well as the frequency of fruit and vegetables consumption among medical students [39].
Cognitive and behavioural efforts to promote selfefficacy and optimism, as well as raising the level of life satisfaction can be useful in improving the nutrition of various population groups, including athletes. High levels of sense of efficacy, optimism, and life satisfaction are important health resources conducive to active care for one's health, including more rational dietary behaviours of athletes. The rationalization of nutritional management of athletes requires its monitoring, with the consideration of the discussed individual characteristics. At the same time, however, owing to the incompleteness and ambiguity of the obtained results, it is necessary to emphasise the need for further research on the psychological determinants of the nutritional behaviour of athletes; the research should involve a larger number of participants and a wider spectrum of psychological and nutritional analyses.

\section{Conclusions}

1. Among professional athletes training individual disciplines, nutritional mistakes were found, particularly related to the low frequency of consuming the recommended food products, such as wholegrain cereal products, vegetables and fruit, dairy products (including those fermented) with reduced fat content, marine fish, and nuts.

2. Among athletes practising individual disciplines, the frequency of consuming some groups of food products depended on sex, age, type of performed discipline, and the level of self-efficacy, dispositional optimism, and life satisfaction. The scale of rational food choices increased along with age and with higher intensification of the analysed personal resources.

3. Rationalization of the diet in athletes training individual sports disciplines should also take sex, age, type of discipline, and psychological characteristics into account, including the level of generalized efficacy, dispositional optimism, and life satisfaction.

\section{Disclosure statement}

The author does not have any financial interest and did not receive any financial benefit from this research.

\section{Conflict of interest}

The author states no conflict of interest.

\section{References}

1. Kreider RB, Wilborn CD, Taylor L, Campbell B, Almada AL, Collins R, et al. ISSN exercise \& sport nutrition review: research \& recommendations. J Int Soc Sports Nutr. 2010;7:7; doi: 10.1186/1550-2783-7-7. 
2. Potgieter S. Sport nutrition: a review of the latest guidelines for exercise and sport nutrition from the American College of Sport Nutrition, the International Olympic Committee and the International Society for Sports Nutrition. S Afr J Clin Nutr. 2013;26(1):6-16; doi: 10.1080/16070658.2013.11734434.

3. Thomas DT, Erdmann KA, Burke LM. Position of the Academy of Nutrition and Dietetics, Dietitians of Canada, and the American College of Sports Medicine: nutrition and athletic performance. J Acad Nutr Diet. 2016; 116(3):501-528; doi: 10.1016/j.jand.2015.12.006.

4. Burke LM. A food pyramid for Swiss athletes. Int J Sport Nutr Exerc Metab. 2008;18(4):430-437; doi: 10.1123/ ijsnem.18.4.430.

5. Yavari A, Javadi M, Mirmiran P, Bahadoran Z. Exercise-induced oxidative stress and dietary antioxidants. Asian J Sports Med. 2015;6(1):e24898; doi: 10.5812/ asjsm.24898.

6. Remick AK, Polivy J, Pliner P. Internal and external moderators of the effect of variety on food intake. Psychol Bull. 2009;135(3):434-451; doi: 10.1037/a0015327.

7. Birkenhead KL, Slater G. A review of factors influencing athletes' food choices. Sports Med. 2015;45(11): 1511-1522; doi: 10.1007/s40279-015-0372-1.

8. Juczyński Z. Measurement tools in health promotion and psychology [in Polish]. Warszawa: Pracownia Testów Psychologicznych Polskiego Towarzystwa Psychologicznego; 2009.

9. Gacek M, Frączek B. Nutritional evaluation of junior football players depending on the global level of self-efficacy of the athletes. Med Sportiva. 2013;17(2):72-75.

10. Gacek M. Association between self-efficacy and dietary behaviours of American football players in the Polish clubs in the light of dietary recommendations for athletes. Rocz Panstw Zakl Hig. 2015;66(4):361-366.

11. Gacek M. Sense of generalized self-efficacy versus dietary choices of young women engaged in fitness for recreational purposes [in Polish]. Med Og Nauk Zdr. 2016;22(3):227-231; doi: 10.5604/20834543.1220527.

12. Gacek M. The sense of life satisfaction versus dietary choices of young women doing fitness for recreational purposes. Rocz Panstw Zakl Hig. 2017;68(1):77-81.

13. Frączek B, Gacek M. Frequency of consumption of food products by a group of Polish athletes in relationship to the qualitative recommendations included in the Swiss food pyramid. Med Sportiva. 2013;17(1):13-17; doi: 10.5604/17342260.1041880.

14. Kopeć A, Nowacka E, Klaja A, Leszczyńska T. Assessment of selected food frequency intake in football players [in Polish]. Probl Hig Epidemiol. 2013;94(1):151-157.

15. Ono M, Kennedy E, Reeves S, Cronin L. Nutrition and culture in professional football. A mixed method approach. Appetite. 2012;58(1):98-104; doi: 10.1016/j. appet.2011.10.007.

16. Alaunyte I, Perry JL, Aubrey T. Nutritional knowledge and eating habits of professional rugby league players: does knowledge translate into practice? J Int Soc Sports Nutr. 2015;12:18; doi: 10.1186/s12970-015-0082-y.

17. Jenner SL, Trakman G, Coutts A, Kempton T, Ryan S, Forsyth A, et al. Dietary intake of professional Australian football athletes surrounding body composition assessment. J Int Soc Sports Nutr. 2018;15:43; doi: 10.1186/s12970-018-0248-5.

18. Baranauskas M, Stukas R, Tubelis L, Žagminas K, Šurkienė G, Švedas E, et al. Nutritional habits among high-performance endurance athletes. Medicina. 2015; 51(6):351-362; doi: 10.1016/j.medici.2015.11.004.

19. Głąbska D, Jusińska M. Analysis of the choice of food products and the energy value of diets of female middle- and long-distance runners depending on the selfassessment of their nutritional habits. Rocz Panstw Zakl Hig. 2018;69(2):155-163.

20. Appiah-Dwomoh EK, Carlsohn A, Mayer F. Assessment of dietary intake of long-distance race car drivers - a pilot study. Sports. 2018;6(4):118; doi: 10.3390/ sports6040118.

21. Nunes CL, Matias CN, Santos DA, Morgado JP, Monteiro CP, Sousa M, et al. Characterization and comparison of nutritional intake between preparatory and competitive phase of highly trained athletes. Medicina. 2018;54(3):41; doi: 10.3390/medicina54030041.

22. Tota Ł, Pilch W, Hodur M, Sagalara A. Assessment of diet of young medium- and long-distance runners. Med Sportiva. 2013;17(1):18-23; doi: 10.5604/1734 2260.1041883.

23. Wierniuk A, Włodarek D. Estimation of energy and nutritional intake of young men practicing aerobic sports. Rocz Panstw Zakl Hig. 2013;64(2):143-148.

24. Pilis K, Michalski C, Zych M, Pilis A, Jelonek J, Kaczmarzyk A, et al. A nutritional evaluation of dietary behaviour in various professional sports. Rocz Panstw Zakl Hig. 2014;65(3):227-234.

25. Stellingwerff T. Competition nutrition practices of elite ultramarathon runners. Int J Sport Nutr Exerc Metab. 2016;26(1):93-99; doi: 10.1123/ijsnem.2015-0030.

26. Gruszczyńska M, Bąk-Sosnowska M, Plinta R. Health behaviors of amateur mountain bike athletes. Hum Mov. 2018;19(2):60-67; doi: 10.5114/hm.2018.74060.

27. Emanuel AS, McCully SN, Gallagher KM, Updegraff JA. Theory of planned behavior explains gender difference in fruit and vegetable consumption. Appetite. 2012;59(3): 693-697; doi: 10.1016/j.appet.2012.08.007.

28. Iglesias-Gutiérrez E, García-Rovés PM, García A, Patterson AM. Food preferences do not influence adolescent high-level athletes' dietary intake. Appetite. 2008; 50(2-3):536-543; doi: 10.1016/j.appet.2007.11.003.

29. Łagowska K, Woźniewicz M, Jeszka J. Comparison of eating habits among students with admitted sex and level of physical activity [in Polish]. Rocz Panstw Zakl Hig. 2011;62(3):335-342.

30. Gacek M. Dietary habits and locus of control assessed in middle-school pupils from the Malopolska region of Poland. Rocz Panstw Zakl Hig. 2013;64(2):129-134. 
31. Pelly FE, Burkhart SJ, Dunn P. Factors influencing food choice of athletes at international competition events. Appetite. 2018;121:173-178; doi: 10.1016/j.appet.2017. 11.086.

32. Gacek M. Analysis of dietary habits among junior and senior soccer players as seen against qualitative recommendations for athletes [in Polish]. Probl Hig Epidemiol. 2018;99(3):289-293.

33. Carver CS, Scheier MF, Segerstrom SC. Optimism. Clin Psychol Rev. 2010;30(7):879-889; doi: 10.1016/j. cpr.2010.01.006.

34. Potempa K. Optimism and health [in Polish]. Med Og Nauk Zdr. 2013;19(2):130-134.

35. Gacek M. Selected personal resources vs. eating habits of female fitness trainers [in Polish]. Probl Hig Epidemiol. 2017;98(2):159-163.

36. Lipowski M. Level of optimism and health behavior in athletes. Med Sci Monit. 2012;18(1):CR39-CR43; doi: 10.12659/MSM.882200.

37. Posadzki P, Stockl A, Musonda P, Tsouroufli M. A mixed-method approach to sense of coherence, health behaviors, self-efficacy and optimism: towards the operationalization of positive health attitudes. Scand J Psychol.2010;51(3):246-252; doi: 10.1111/j.1467-9450. 2009.00764.x.

38. Kosiba G, Gacek M, Bogacz-Walancik A, Wojtowicz A. Health-related behaviours and perceived life satisfaction in the academic youth of pedagogical subjects [in Polish]. Teraźniejszość - Człowiek - Edukacja. 2017; 20(2):79-93.

39. Lesani A, Mohammadpoorasl A, Javadi M, Esfeh JM, Fakhari A. Eating breakfast, fruit and vegetable intake and their relation with happiness in college students. Eat Weight Disord. 2016;21(4):645-651; doi: 10.1007/ s40519-016-0261-0. 